\title{
Quality management system design of vocational services in PM College based on ISO 9001:2015
}

\author{
Karina Gisela Napitupulu ${ }^{1, *}$, Mohammad Mi'radj Isnaini ${ }^{1}$, and Dradjad Irianto $^{1}$ \\ ${ }^{1}$ Industrial Engineering, Institut Teknologi Bandung, Ganesa No.10, Bandung, Indonesia
}

\begin{abstract}
Vocational college institution has a substantial contribution to support the development of industrial human resources in Indonesia. PM College as one the reputable vocational college provides educational services for students and training services for industry employees. PM College has a focus to provide customer satisfaction. PM College's customers consist of industries mainly from manufacturing businesses. To guarantee the educational process, PM College has been applying the quality management system based on ISO 9001:2008. The current challenge of the PM College is to apply the latest ISO 9001: 2015 which is a revision of the previous version standard. ISO 9001: 2015 has some changes made as a form of adjustment. The institution feels the need to make improvements to the current quality management system to provide the satisfaction to customers, both from the industry and university students and to compete with the other polytechnic as well. This paper proposes an approach to prepare and analyze the organization in fulfilling the requirements of ISO 9001:2015. Several data processing and analysis were conducted to identify clauses' fulfillment between activity and document of the organization in meeting the ISO 9001:2015. The results of data processing and analysis show that PM College needs to make improvements in business processes and has not met ten clause requirements of ISO 9001:2015. Several adjustments were proposed to the business process and ten clauses to assist PM College in preparing the ISO 9001:2015 certification.
\end{abstract}

\section{Introduction}

The manufacturing industry is one of the driving force of industry in Indonesia. Polytechnics as educational institutions have a goal to produce industrial graduates who can work with professionals from the different field of expertise. As a manufacturer of human resources for the manufacturing industry, polytechnics are expected to provide the competent workforce. To produce a competent workforce, polytechnic need to pay attention and control the quality of their institution by applying quality management system.

PM College provides educational services for students and training services for industry and general employees. PM College has a focus to provide customer satisfaction.

\footnotetext{
*Corresponding author: iis@mail.ti.itb.ac.id
} 
Customers of PM College education services consist of industry and business world who employ PM College graduates in their companies and students who receive PM College education services. PM College customer satisfaction is still below the level of interests and customer expectations indicates that PM College needs to strive to improve the quality of its services with ISO 9001 quality management system consistently. Therefore, it is necessary for PM College to improve the quality of education services and increase added value for customers who choose PM College by updating the current ISO 9001:2008 standard to the new ISO 9001:2015 to improve competitiveness among another polytechnic [1].

Moreover, the time allowed for the company to make the transition is three years after the latest standards are released. Such provision causes PM College to immediately update the ISO standard used by revising its quality management system to be recognized and recertified. Therefore, PM College need to update the quality management system based on ISO 9001: 2015 to have guaranteed quality and can compete with competitors and answer customer expectation as education service user in PM College.

\section{Theoretical Background}

ISO is an independent international and non-governmental organization composed of 162 national standard bodies. According to ISO [2], the quality management system is a management system to direct and control the organization to meet the needs or defined expectations by paying attention to quality. International standards such as ISO 9000, ISO 9001 and other ISO related quality management standards encompass on several quality management principles: customer focus, leadership, people engagement, process approach, continuous improvement, relationship management and decision making with the factual approach.

The implementation of the quality management system is a strategic decision for the organization because it can help the organization to improve performance and design a basis for implementing sustainable development [3]. The organization may well-received higher benefits by implementing the quality management system to improve organizational consistency in providing products and services [4]. By meeting the customer requirements and improving customer satisfaction, the organization can identify risks and opportunities related to the context and objectives of the organization in demonstrating the ability to meet the standards [5].

ISO 9001 comprises the requirements that the organization needs to meet the standards of the quality management system by providing products and services to meet customer requirements. ISO 9001 covers different types of organizations with their respective activities and sizes. ISO 9001 has undergone several revisions from 1994, 2000, 2008 and up to date in 2015. At ISO 9001: 2015, there are three basic concepts used: process approach, PDCA cycle, and risk-based thinking. ISO 9001:2015 consist of 10 clauses namely: (1) Scope; (2) Normative Reference; (3) Terms and Definitions; (4) Organizational Context; (5) Leadership; (6) Planning; (7) Support; (8) Operational; (9) Performance Evaluation; 10. Improvements [6].

\section{Proposed Methodology}

The proposed stages to design and analyze the existing quality management system on PM College are depicted in Figure 1. The literature study was conducted by reading research, articles, journals, and books related to the quality management system issues especially ISO 9001: 2008 and ISO 9001: 2015. Data collection is conducted on the quality management 
system that the organization currently implements is ISO 9001: 2008. The data collected in the form of primary data and secondary data from the organization. Primary data collection conducted is an interview with stakeholders about the internal and external conditions of the organization, business processes and the implementation of quality management systems so far in the organization. While secondary data is obtained from organizational documents such as organizational profiles, organizational structures, and quality management system documents related to the application of ISO 9001: 2008.

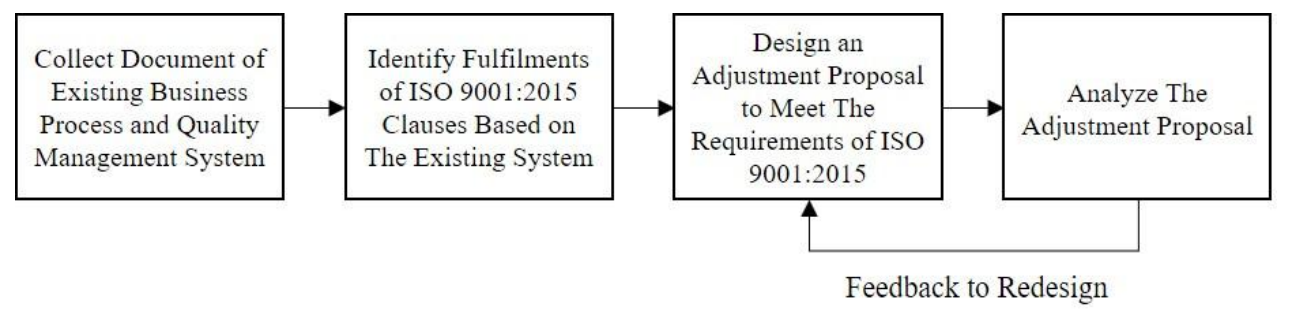

Figure 1. The proposed methodology to adjust the current system to meet the standard of ISO 9001:2015

Based on the data collected, data processing is performed by identifying the requirements of ISO 9001: 2015 clauses that have not been met through business processes and quality management system documents. It then identifies by checking the achievement to meet the requirements in each clause of ISO 9001: 2015. The results of clause identification indicate business process activities that have not met the ISO 9001: 2015 clause and documentation that has not been reached. The results of identification form the basis for designing documents to support compliance with ISO 9001: 2015 requirements. The design of the proposed quality management system is conducted by designing and improving the current quality management system documents. The thing done is the design of the proposed quality guidelines as one of the documented information that should be owned by every organization that implements ISO 9001.

The analysis stage includes an analysis of the organization's business process adjustments to meet the requirements contained in ISO 9001: 2015, an analysis of compliance with ISO 9001: 2015 clauses based on actual organizational conditions and design results, and an analysis of compliance with documentation required under ISO 9001: 2015. Lastly performed implementation analysis and potential barriers which may arise in the implementation of the quality management system in the organization. In the analysis process, validation is performed to determine whether the designed solution meets the requirements of ISO 9001: 2015 clauses and is relevant to the actual condition of the organization. The validation activity is done to discuss the result of the problem owner design that is PM College Quality Management Team.

\section{Analysis}

\subsection{Business process categorization based on ISO 9001 :2015}

The business process shows activities in an interconnected organization to produce a product or service. Business process mapping is carried out to meet the requirements of ISO 9001:2015 relating to the process approach. Every process found in the organization needs to be addressed to meet customer satisfaction. Figure 2 shows the business process which applies to the existing services in PM College today. 


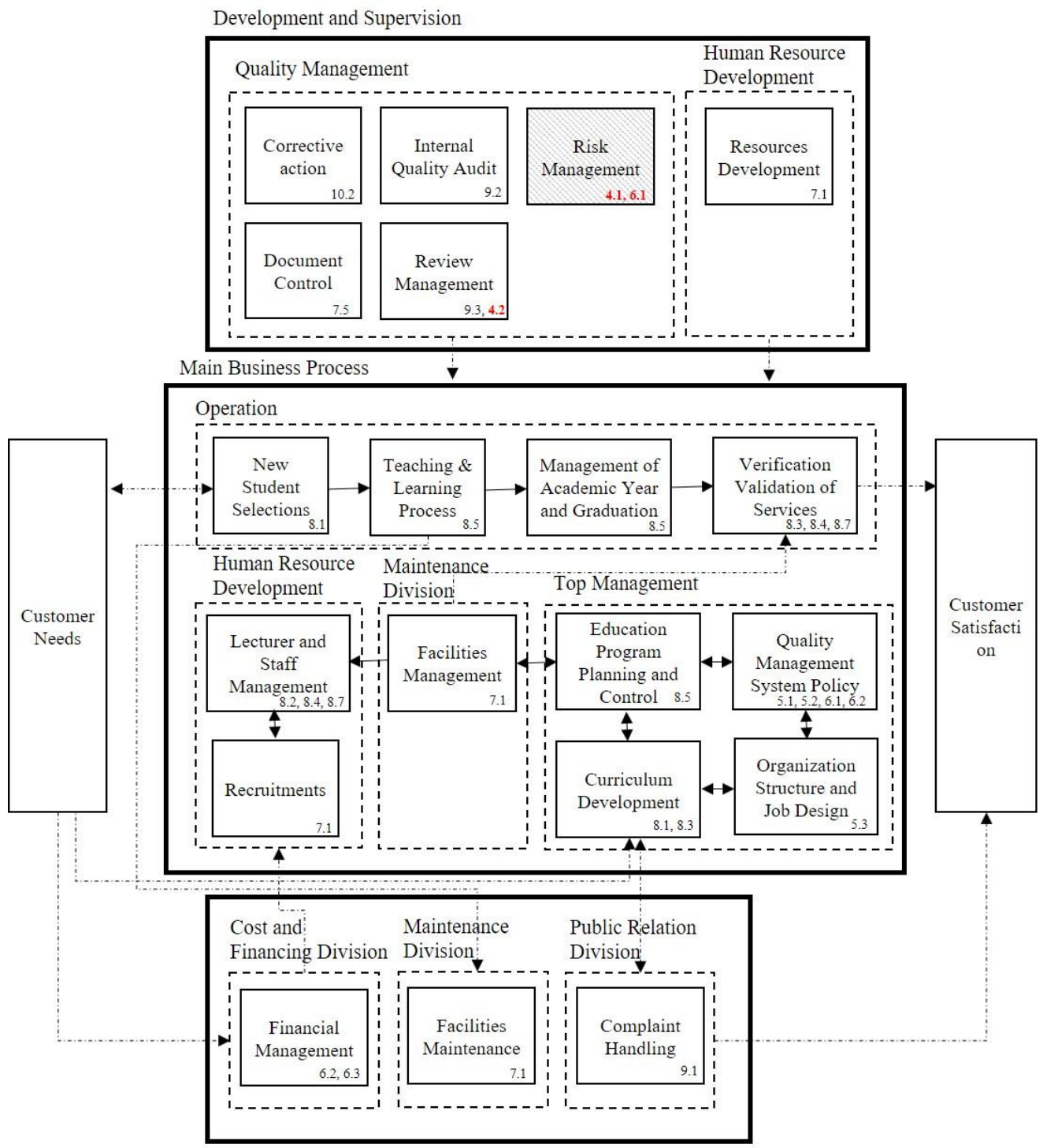

Secondary Business Process

Figure 2. The existing of PM College business processes.

By analyzing the business process linkage with the clause of ISO 9001: 2015, the following clause are not yet available: Clause 4.1 on the understanding of the organization and its context; Clause 4.2 on understanding the needs and expectations of the parties concerned; Clause 6.1 on measures to deal with risks and opportunities, and; Clause 7.1.6 concerning organizational knowledge. The related activities of clauses 4.1 and 6.1 have not been implemented in the quality management system therefore it is necessary to add activities to the company's business processes. The related activities of clauses 4.1 and 6.1 
were added to the Quality Management Representative section in the form of risk management. The result of business process improvement is depicted also in Figure 2.

\subsection{Fulfillment of ISO 9001:2015}

To find out the readiness of PM College to fulfill ISO 9001:2015, the analysis regarding the conformity of the management of the current quality management system with the clause requirements at ISO 9001: 2015 was performed. Table 1 describes the result of a comprehensive analysis and recommendation on the current quality management system.

Table 1. Unidentified clause fulfillment.

\begin{tabular}{|c|c|c|}
\hline No & Clause & Recommendation \\
\hline \multirow{2}{*}{4.1} & \multirow{2}{*}{$\begin{array}{l}\text { Understanding the Organization and its } \\
\text { Context }\end{array}$} & Repair manual quality \\
\hline & & Proposed document form external and internal issue identification \\
\hline \multirow[b]{2}{*}{4.2} & \multirow{2}{*}{$\begin{array}{l}\text { Understand the needs and expectations of } \\
\text { the interested parties }\end{array}$} & Repair manual quality \\
\hline & & $\begin{array}{l}\text { Proposed documents of identification form of interested parties and } \\
\text { requirements }\end{array}$ \\
\hline 4.3 & $\begin{array}{l}\text { Determine the scope of the quality } \\
\text { management system }\end{array}$ & Quality manual adjustment \\
\hline 4.4 & Quality management systems and processes & Improved document input process output \\
\hline 5.1 .2 & Customer focus & Repair manual quality \\
\hline \multirow{3}{*}{6.1} & \multirow{3}{*}{$\begin{array}{l}\text { Measures to deal with risks and } \\
\text { opportunities }\end{array}$} & Design of risk identification form \\
\hline & & Addition of risk matrix form \\
\hline & & The design of risk management procedures \\
\hline 7.1 .1 & Resource & Repair manual quality \\
\hline \multirow{2}{*}{ 7.1.6 } & \multirow{2}{*}{ Organizational Knowledge } & The design of organizational knowledge procedures \\
\hline & & Designing an identification form for organizational knowledge needs \\
\hline \multirow{2}{*}{9.3 .2} & \multirow{2}{*}{ Management review } & Quality manual adjustment \\
\hline & & The design of management review procedures \\
\hline
\end{tabular}

\section{Analysis and Discussion}

\subsection{Business process categorization based on ISO 9001 :2015}

In the application of ISO 9001: 2015, an understanding of the organization's business processes is required. The known business process is needed because ISO 9001: 2015 applies a process-based and risk-based thinking approach to every process undertaken to provide products or services. Based on the observations made to understand the business process of PM College that has been certified ISO 9001: 2008, there is no risk management activity because this activity is not required on the requirements of ISO 9001: 2008. However, risk management activities are required requirements in ISO 9001: 2015 so organizations need to add these activities to business processes. The addition to this business process shows that PM College runs several activities related to risk management in the processes and quality management system of the company.

The addition of new risk management activities is suggested in the process of development and management of business processes PM College. According to ISO [7], risk management activities are undertaken so that the organization can determine the factors that have the potential to cause the organization's quality management processes and systems to deviate from expected results and take precautions to mitigate impacts and maximize emerging opportunities. 


\subsection{Design implementation of the existing quality management system}

Implementation of ISO 9001: 2015 raises some impacts on the organization. The impact of implementation is divided into two: administrative and organizational impacts. The administrative compound is related to changes to the applicable standards, procedures, work processes and policies in the organization. Organizational impact on the organization as an example of the addition of personnel and changes to the organizational structure. For the impact of proposed improvements from administrative impacts, adjustments made to PM College need to make changes to the company documents that is the creation of new procedures, improvements to the quality manual and document improvements shown in Table 2.

Table 2. Improvements on unidentified clause

\begin{tabular}{|c|c|l|}
\hline $\begin{array}{c}\text { Type of proposed } \\
\text { improvement }\end{array}$ & No & \multicolumn{1}{|c|}{ Clause } \\
\hline $\begin{array}{c}\text { Creating a new } \\
\text { procedure }\end{array}$ & 1 & 6.1 Measures to deal with risks and opportunities \\
\cline { 2 - 4 } & 2 & 7.1 .6 Organizational knowledge \\
\hline \multirow{4}{*}{$\begin{array}{c}\text { Repair manual } \\
\text { quality }\end{array}$} & 3 & 4.3 Establish the scope of the quality management system \\
\cline { 2 - 4 } & 4 & 5.1 .1 Leadership and commitment \\
\cline { 2 - 4 } & 5 & 5.1 .2 Focus on the customer \\
\cline { 2 - 4 } & 6 & 7.1 Provision of resources \\
\cline { 2 - 3 } & 7 & 9.3 .2 Input management review \\
\hline \multirow{4}{*}{ Document repair } & 8 & 4.1 Understand the organization and its context \\
\cline { 2 - 4 } & 9 & 4.2 Understand the needs and expectations of interested parties \\
\cline { 2 - 3 } & 10 & 4.4 Quality management systems and processes \\
\cline { 2 - 3 } & 11 & 9.3 .2 Input management review \\
\hline
\end{tabular}

The results of the proposed document improvement are discussed together with the Quality Management Team as the party of PM College and evaluated and approved by the PM College regarding document aspect. Furthermore, the organization needs to verify the proposed documents to know whether the documents are designed as needed and not redundant with other documents. Implementation of verification activities may be performed by the head and staff of the relevant sections. If the document has passed the verification stage, numbering on the proposed new document and the new document register in the document list can be made. In addition to the preparation of new documents that need to be done, the company also needs to adjust the quality manual of the company.

\section{Conclusion}

The design of quality management system that is done on education service at Bandung State Manufacturing Polytechnic done by renewing the previous quality management system which refers to ISO 9001: 2008 standard. The design is done by adjusting business processes and adjusting the requirements. Adjustment requirements can be documented adjustments and statement adjustments in the quality manual. This adjustment is made by ISO 9001: 2015. From the results of the analysis, found ten clauses that are not by the requirements of ISO 9001: 2015 are clauses 4.1, 4.2, 4.3, 4.4, 5.1.1, 5.1.2, 6.1, 7.1.1, 7.1.6 and 9.3.2. 


\section{References}

1. BSI. Moving from ISO 9001:2008 to ISO 9001:2015. London: BSI Group. (2014).

2. ISO. International Organization for Standardization 9001:2015 Quality Management. Geneva: ISO. (2015).

3. B. Purushothama., Effective Implementation of Quality Management Systems. India: Woodhead Publishing India Pvt. Ltd. (2010).

4. Psomas, E. L. (2013). The effectiveness of the ISO 9001 quality management system in service companies. Total Quality Management \& Business Excellence, Vol. 24, No. 7, 769-781.

5. A. Lester., Project Management, Planning, and Control (6th Edition ed.). USA: Elsevier. (2014)

6. BSI. BSI Training Catalogue. London: BSI Group. (2017).

7. ISO. International Organization of Standard 31000:2009 Risk Management. Geneva: ISO. (2009). 